\title{
Production of L-Theanine Using Escherichia coli Whole-Cell Overexpressing p-Glutamylmethylamide Synthetase with Baker's Yeast
}

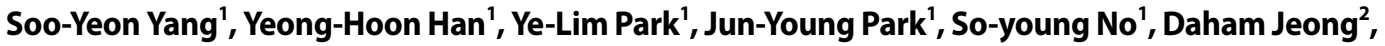 \\ Saerom Park' ${ }^{1}$ Hyung Yeon Park', Wooseong Kim ${ }^{3}$, Seung-Oh Seo ${ }^{4 *}$, and Yung-Hun Yang ${ }^{1,5 *}$ \\ 'Department of Biological Engineering, College of Engineering, Konkuk University, Seoul 05029, Republic of Korea \\ ${ }^{2}$ Department of Bioscience and Biotechnology, Konkuk University, Seoul 05029, Republic of Korea \\ ${ }^{3}$ College of Pharmacy and Graduate School of Pharmaceutical Sciences, Ewha Womans University Seoul 03760 , \\ Republic of Korea \\ ${ }^{4}$ Department of Food Science and Nutrition, The Catholic University of Korea, Bucheon 14662, Republic of Korea \\ ${ }^{5}$ Institute for Ubiquitous Information Technology and Applications, Konkuk University, Seoul 05029, Republic of Korea
}

L-Theanine, found in green tea leaves has been shown to positively affect immunity and relaxation in humans. There have been many attempts to produce L-theanine through enzymatic synthesis to overcome the limitations of traditional methods. Among the many genes coding for enzymes in the L-theanine biosynthesis, glutamylmethylamide synthetase (GMAS) exhibits the greatest possibility of producing large amounts of production. Thus, GMAS from Methylovorus mays No. 9 was overexpressed in several strains including vectors with different copy numbers. BW25113(DE3) cells containing the $\mathrm{pET} 24 \mathrm{ma}:$ :gmas was selected for strains. The optimal temperature, $\mathrm{pH}$, and metal ion concentration were $50^{\circ} \mathrm{C}$, 7 , and $5 \mathrm{mM} \mathrm{MnCl}_{2}$, respectively. Additionally, ATP was found to be an important factor for producing high concentration of L-theanine so several strains were tested during the reaction for ATP regeneration. Baker's yeast was found to decrease the demand for ATP most effectively. Addition of potassium phosphate source was demonstrated by producing 4-fold higher L-theanine. To enhance the conversion yield, GMAS was additionally overexpressed in the system. A maximum of $198 \mathrm{mM}$ L-theanine was produced with $16.5 \mathrm{mmol} / \mathrm{l} / \mathrm{h}$ productivity. The whole-cell reaction involving GMAS has greatest potential for scale-up production of L-theanine.

Received: October 21, 2019 Accepted: February 21, 2020 First published online: February 25, 2020 *Corresponding authors S.-O.S

Phone: +82-2-2164-4316 Fax: $+82-2-2164-6583$ E-mail: seokor@konkuk.ac.kr Y.H.Y.

Phone: +82-2-450-3936 Fax: +82-2-3437-8360 E-mail: drsos@catholic.ac.kr

Supplementary data for this paper are available on-line only at http://jmb.or.kr.

pISSN 1017-7825 eISSN 1738-8872

Copyright(C) 2020 by The Korean Society for Microbiology and Biotechnology
Keywords: L-theanine, whole-cell biocatalyst, baker's yeast, ATP regeneration

\section{Introduction}

Tea is widely consumed worldwide because of its delicate flavor and physiological benefits because it contains many components such as catechins, caffeine, vitamins, L-theanine, and mineral elements [1]. Among them, Ltheanine, also known as $\gamma$-glutamylethylamide, is naturally found in Japanese green tea leaves and contributes to the quality of green tea [2]. The physiological activities of $\mathrm{L}$-theanine include effects as remarkable relaxation in humans, enhancing immunity, and decreasing anti-oxidative stress and diseases [3]. Accordingly, the demand for L-theanine is increasing annually and large scale-production methods are necessary to supply L-theanine to the food and pharmaceutical industry [4].

Many methods for the synthesis of L-theanine have been investigated extensively such as extraction from tea leaves [5,6], chemical synthesis [7], and enzymatic synthesis [8,9]. Direct extraction has numerous limitations for large-scale production such as its high cost, time-consuming steps, and demanding operational processes. Additionally, the chemically synthesized product is a racemic mixture of the $\mathrm{L}$-form and D-form, thereby reducing product purity and requiring additional purification. [10]. Thus, biological synthesis of L-theanine has attracted much attention recently.

The enzymes involved in L-theanine production include $\gamma$-glutamyltranspeptidase (GGT), L-glutaminase, Lglutamine synthetase (GS), or $\gamma$-glutamylmethylamide synthetase (GMAS). Under overexpression of GGT in E. coli followed by purification, $156 \mathrm{mM}$ L-theanine was produced using glutamine and ethylamine as substrates [11]. Additionally, production of $126 \mathrm{mM}$ L-theanine was achieved using purified L-glutaminase from Pseudomonas nitroreducens through a $\gamma$-glutamyl transfer reaction of glutamine [12]. However, conversion yields remain low because GGT and L-glutaminase tend to hydrolyze L-glutamine to other $\gamma$-glutamyl derivatives [13]. Liu et al. 
produced $254 \mathrm{mM}$ L-theanine using GMAS from Methylovorus mays No. 9 strain by glutamate and ethylamine through the hydrolysis of ATP. Compared to other enzymes, GMAS shows greater potential for producing high concentrations of L-theanine [14].

Many synthetases require high ATP concentrations during catalysis to ensure high titers of various products $[15,16]$. Therefore, systems for ATP regeneration have been investigated [17-19]. These methods use a variety of enzymes capable of synthesizing ATP, such as polyphosphate kinase, acetate kinase, and pyruvate kinase [20, 21]. However, the use of pyruvate kinase and acetate kinase is limited by the high cost of phosphoryl donors and their product inhibition activity. Additionally, both systems possess broad substrate specificities, which can regenerate other types of nucleosides and 2'-deoxynucleoside triphosphates, such as GTP, UTP, and CTP [22]. The system using polyphosphate kinase shows low activity towards specific substrates, so that it causes poor availabilities. As an alternative to ATP regeneration, the use of baker's yeast has been considered in many studies [23-25]. Sugarfermentative systems can effectively produce ATP as an energy source from AMP or ADP, effectively [26]. Therefore, the excessive consumption of ATP can be overcome by taking advantage of the energy transfer system of baker's yeast in an ATP-dependent reaction [27, 28].

In this study, we developed a whole-cell biotransformation system for production of L-theanine. GMAS from M. mays No. 9 was overexpressed in E. coli BW25113 and was used for the synthesis of L-theanine using glutamate and ethylamine as substrates. Compared to conventional usage of purified enzymes, this whole-cell system can mitigate complex purification processes and decrease operational costs to enhance economic feasibility. Through this result, the cell cultivation and reaction conditions were optimized to achieve a high titer of L-theanine. Additionally, we found that ATP and different phosphate sources affected the reaction. To our knowledge, this is the first application of whole-cell overexpressed by GMAS for L-theanine production.

\section{Materials and Methods}

\section{Reagents}

Sodium L-glutamate monohydrate $(>99 \%)$ and ethylamine hydrochloride $(>98 \%)$ were purchased from SigmaAldrich Co. (USA). L-Theanine ( $>98 \%$ ) and Adenosine $5^{\prime}$-triphosphate disodium salt hydrate were obtained from Tokyo Chemical Industry Co. (Japan). Baker's yeast was purchased from ACH Food Companies, Inc. (Oakbrook Terrace, USA). Tris hydrochloride ( $>99 \%)$, Tris-base ( $>99.9 \%)$, sodium borate decahydrate $(>99 \%)$, isopropyl- $\beta$ d-thiogalactopyranoside (>99\%), and other medium components were obtained from Biosesang Co. (Korea). Diethyl ethoxymethylenemalonate (DEEMM) was purchased from Fluka Co. (Japan) for the derivatization reaction.

\section{Bacterial Strains, Plasmids, and Media}

E. coli DH5 a strain was used as the host for gene cloning. Based on the sequence of GMAS from Methylovorus mays No. 9, GMAS was codon-optimized and synthesized by Cosmogenetech (Korea) and utilized as the PCR template for gene amplification. Amplified genes were inserted into pET24ma (constructed by Dr. David Sourdive, Pasteur Institute, France) containing a p15A replication origin, pXMJ19, and pMAL vectors using restriction enzymes and T4-ligase. The constructed plasmid was transformed into competent $E$. coli cells to prepare the whole-cell biocatalyst [29]. All bacterial strains and plasmids are provided in Table 1. All E. coli strains were pre-cultured in $5 \mathrm{ml}$ lysogeny broth (LB) medium containing $10 \mathrm{~g} / \mathrm{l}$ tryptone, $5 \mathrm{~g} / \mathrm{l}$ yeast extract, and $5 \mathrm{~g} / \mathrm{l}$ sodium chloride with antibiotics by inoculating a single colony from an agar plate. Cells were cultured in a shaking incubator (Han-Beak Science Co., Korea) at $37^{\circ} \mathrm{C}$ with $200 \mathrm{rpm}$. The pre-culture was inoculated into $50 \mathrm{ml}$ of main culture medium containing antibiotics in a $250-\mathrm{ml}$ baffled Erlenmeyer flask and incubated at $37^{\circ} \mathrm{C}$ with shaking [30, 31]. Upon reaching an $\mathrm{OD}_{600}$ of $0.6-0.7$, the cultures were induced by adding isopropyl $\beta$-d-1thiogalactopyranoside (IPTG) at $0.5 \mathrm{mM}$. The cultures were then incubated at $25^{\circ} \mathrm{C}$ with shaking for $16 \mathrm{~h}$. Cultures were harvested by centrifugation at $5,500 \mathrm{rpm}$ for $10 \mathrm{~min}$ at $4^{\circ} \mathrm{C}$, and the cell pellet was washed with deionized water [32]. The cell suspension was stored at $4^{\circ} \mathrm{C}$ until further use and referred to as whole-cell.

\section{Whole-Cell Reaction}

GMAS activity was evaluated using the whole-cell as a catalyst. The reaction was performed with $100 \mathrm{mM}$ glutamate, $100 \mathrm{mM}$ ethylamine, $200 \mathrm{mM}$ glucose, $60 \mathrm{mM}$ ATP, $5 \mathrm{mM} \mathrm{MnCl}_{2}, 10 \mathrm{mM} \mathrm{MgCl}_{2}, 300 \mathrm{mM}$ potassium phosphate and $40 \mathrm{mg} / \mathrm{ml}$ baker's yeast. Each parameter was varied to identify the overall optimal reaction conditions. The initial $\mathrm{pH}$ was adjusted to 7 with $5 \mathrm{~N} \mathrm{NaOH}$. Each parameter was varied to identify the optimal reaction conditions. The reaction solution was incubated at $50^{\circ} \mathrm{C}$ for $24 \mathrm{~h}$ in a shaking mixer at 1,200 rpm. The reaction was stopped by heating at $90^{\circ} \mathrm{C}$ for $5 \mathrm{~min}$. The reaction solution was then diluted to a suitable concentration for high-performance liquid chromatography (HPLC, YL-9100; Korea) analysis [33].

\section{Derivatization and HPLC Analysis}

Amine derivatives were prepared in a mixture of $300 \mu \mathrm{l}$ borate buffer $(50 \mathrm{mM}, \mathrm{pH}$ 9), $100 \mu \mathrm{l}$ methanol, $47 \mu \mathrm{l}$ distilled water, $50 \mu$ larget sample, and $3 \mu \mathrm{l}$ DEEMM [34]. The derivatization reaction was performed at $70^{\circ} \mathrm{C}$ for $2 \mathrm{~h}$ to derivatize glutamate, L-theanine, and ethylamine. Analysis by HPLC was performed after derivatization of the reaction products at a UV-absorbance of $284 \mathrm{~nm}$. Chromatographic separation was conducted using a reversephase C18 column (ZORBAX SB-C18 column, $4.6 \times 250 \mathrm{~mm}, 5 \mu \mathrm{m}$ particle size; Agilent Technologies, USA) and the column temperature was maintained at $35^{\circ} \mathrm{C}$. The mobile phase was composed of $100 \%$ acetonitrile (solvent A) and $25 \mathrm{mM}$ sodium acetate buffer $\mathrm{pH} 4.8$ (solvent $\mathrm{B}$ ). The flow rate was maintained at $1 \mathrm{ml} / \mathrm{min}$ and the 
Table 1. List of bacterial strains and plasmids.

\begin{tabular}{|c|c|c|}
\hline Strain/ plasmid & Relevant information & Reference \\
\hline \multicolumn{3}{|l|}{ Bacterial strains } \\
\hline E. coli $\mathrm{DH} 5 \mathrm{a}$ & $\begin{array}{l}\mathrm{F}^{-} \varphi \text { 80lacZ M15 endA recA hsdR }\left(\mathrm{r}_{\mathrm{k}}{ }^{-} \mathrm{m}_{\mathrm{k}}{ }^{-}\right) \text {supE thi gyrA relA } \Delta(\text { lacZYA- } \\
\operatorname{argF}) \mathrm{U} 169\end{array}$ & {$[39]$} \\
\hline E. coli BL21(DE3) & $\mathrm{F}^{-}$ompthsdSB $\left(\mathrm{rB}^{-} \mathrm{mB}^{-}\right)$gal dcm & Novagen \\
\hline E. coli BW25113 & $\begin{array}{l}\mathrm{F}^{\prime} \lambda^{-} \Delta(\text { araD-araB }) 567, \Delta l a c Z 4787(:: \mathrm{rrnB}-3), \text { lambda }^{-}, r p h-1, \\
\Delta(\text { rhaD_rhaB }) 568, \text { hsdR514 }\end{array}$ & CGSC \\
\hline E. coli BW25113(DE3) & $\lambda \mathrm{DE} 3$ lysogen of BW25113 & This study \\
\hline E. coli Shuffle & $\begin{array}{l}\text { fhuA2 lacZ::T7 gene1 [lon] ompT ahpC gal } \lambda \text { att::pNEB3-r1- } \\
\text { cDsbC (Spec', lacIq) } \Delta \text { trxB sulA11 R(mcr-73::miniTn10- } \\
\text { TetS)2 [dcm] R(zgb-210::Tn10 --TetS) endA1 } \Delta \text { gor } \\
\Delta(\text { mcrC-mrr) } 114:: \text { IS10 }\end{array}$ & {$[40]$} \\
\hline E. coli Star ${ }^{\mathrm{TM}}(\mathrm{DE} 3)$ & $\mathrm{F}^{-}$ompT rne 131 lon hsdSB $\left(\mathrm{rB}^{-} \mathrm{mB}^{-}\right)$gal dcm $\lambda(\mathrm{DE} 3)$ & Invitrogen \\
\hline B. subtilis str. 168 & & ATCC \\
\hline C. glutamicum ATCC13032 & & ATCC \\
\hline P. putida KT2440 & & ATCC \\
\hline \multicolumn{3}{|l|}{ Baker's yeast } \\
\hline Plasmid & & \\
\hline pET24ma & $\begin{array}{l}\text { Km }{ }^{\mathrm{r}} .1 \text { MCS site with } \mathrm{T} 7 \text { promoter, lac operator, RBS. P15A replicon. Copy } \\
\text { number: } 10-12\end{array}$ & {$[41]$} \\
\hline pCDF duet 1 & $\begin{array}{l}\text { Spec }{ }^{\mathrm{r}} .2 \text { MCS site with T7 promoter, lac operator, RBS. CloDF13 replicon. } \\
\text { Copy number: } 20-40\end{array}$ & Novagen \\
\hline pRSF duet 1 & $\begin{array}{l}\mathrm{Km}^{\mathrm{r}} .2 \text { MCS site with T7 promoter, lac operator, RBS. RSF1030 replicon } \\
\text { (NTP1). Copy number: }>100\end{array}$ & Novagen \\
\hline pACYC duet 1 & $\begin{array}{l}\mathrm{Cm}^{\mathrm{r}} .2 \mathrm{MCS} \text { site with T7 promoter, lac operator, RBS. P15A replicon. Copy } \\
\text { number: } 10-12\end{array}$ & Novagen \\
\hline pMAL & $\begin{array}{l}\text { Amp }{ }^{\mathrm{r}} \text {. MCS site with tac promoter, lac operator, RBS, ColE1 replicon. Copy } \\
\text { number: } 20\end{array}$ & Novagen \\
\hline pXMJ19 & $\mathrm{Cm}^{\mathrm{r}}$. MCS site with tac promoter, lac operator, pBL1 and pUC replicon & {$[42]$} \\
\hline pET24ma::gmas & gmas of Methylovorus mays No. 9 inserted in pET24ma & This study \\
\hline pCDF duet $1:: g m a s$ & gmas of Methylovorus mays No. 9 inserted in pCDF duet 1 & This study \\
\hline pRSF duet $1::$ gmas & gmas of Methylovorus mays No. 9 inserted in pRSF duet 1 & This study \\
\hline pACYC duet $1:: g m a s$ & gmas of Methylovorus mays No. 9 inserted in pACYC & This study \\
\hline pMAL::gmas & gmas of Methylovorus mays No. 9 inserted in pMAL & This study \\
\hline pXMJ19::gmas & gmas of Methylovorus mays No. 9 inserted in pXMJ19 & This study \\
\hline
\end{tabular}

composition of solvent $A$ to $B(A: B, v / v)$ was changed with the following gradient program: 0 min (20:80), 2 min (25:75), $32 \mathrm{~min}(60: 40), 37 \mathrm{~min}(20: 80), 40 \mathrm{~min}(20: 80)$.

\section{Results and Discussion}

Optimization of Protein Expression Conditions and Cultivation Medium

To obtain a high level of protein expression, GMAS activities in the whole-cell reaction were investigated using various vectors with different copy numbers in several E. coli strains (Fig. 1A). pET24ma (copy numbers 10-12), pXMJ19 (copy number 10-20), and pMAL (copy number 20) were evaluated as GMAS overexpression vectors. The results were indicated as relative conversion, which regards the highest value as $100 \%$ conversion. Results

A

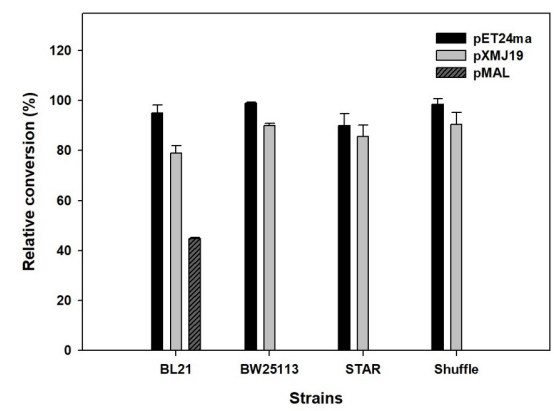

B

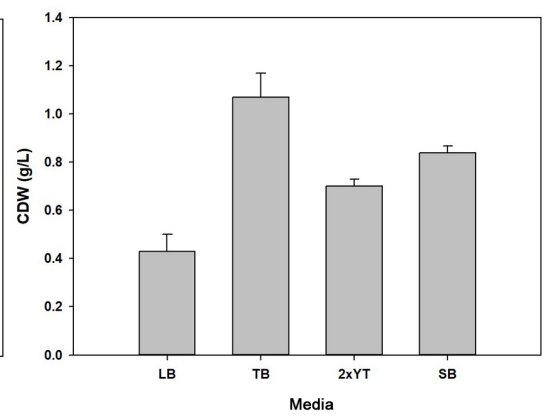

C

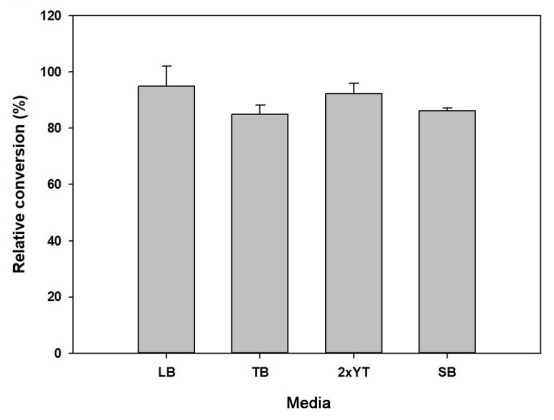

Fig. 1. Optimization of expression and cultivation conditions. GMAS activities were compared in several expression strains containing vectors with different copy numbers for producing L-theanine (A). Cultivation medium were tested by comparing cell dry weight (B) and relative conversion of substrates $(\mathbf{C})$. The results were indicated as relative conversion, which regards the highest value as $100 \%$ conversion. 
showed that all strains containing the pET24ma::gmas exhibited the highest activities. The pMAL::gmas only exhibited activity in the BL21 strain. When comparing GMAS overexpression using pET24ma and pXMJ19, GMAS overexpression with pET24ma showed slightly higher activities in all expression strains. Additionally, evaluation of the pCDF::gmas, pACYC::gmas, and pRSF::gmas, revealed no activities. To explain these results, SDS-PAGE was performed to see GMAS expression level. However, the expression levels from the three kinds of vectors were much lower than those from vectors that showed activity (data not shown). Therefore, we decided to use BW25113 harboring pET24ma::gmas in further experiments.

After selecting the expression vector and strains, we tested various expression media because it can affect cell growth and expression levels [35]. Several media were compared, such as terrific broth (TB), 2xYT, and super broth (SB), which contain higher nitrogen levels than LB media, which is commonly used for E. coli cultivation. The results revealed that TB showed the greatest influence on cell growth after $24 \mathrm{~h}$ of culture (Fig. 1B). The cell dry weight (CDW) by TB was the 2.5, 1.6 and 1.3-fold higher than those grown in LB, $2 x Y T$, and SB, respectively. However, the cell activity after cultivation in TB was slightly lower than that in LB and 2xYT (Fig. 1C). However, it is inefficient to use cells with a low growth rate but slightly higher activities from an industrial perspective. Therefore, TB was utilized to prepare the biocatalyst.

Optimization of Whole-Cell Reaction with Temperature, $\mathrm{pH}$, and Metal ions

To increase the conversion yields of the whole-cell reaction, reaction conditions considered as key factors were optimized. Reaction temperatures ranging from $20-80^{\circ} \mathrm{C}$ were tested to determine the optimal temperature (Fig. 2A). The highest activity was observed at $50^{\circ} \mathrm{C}$, which differs from a previous report that showed an optimal temperature of $37^{\circ} \mathrm{C}$ [14]. This may be because our study used a whole-cell as biocatalyst rather than purified enzyme. A whole-cell bioconversion system generally possesses advantages such as robustness against harsh reaction conditions and higher stability and storability than purified enzymes [36]. The optimal $\mathrm{pH}$ was also studied to enhance production of L-theanine (Fig. 2B). Various initial pH values were tested from 5.5 to 11 , which were adjusted by adding Tris- $\mathrm{HCl}$ buffer and $\mathrm{NaOH}$ solution. The activity increased gradually until pH 7 . However, the activity started to decrease from $\mathrm{pH} 7$ and no activity observed at $\mathrm{pH} 10$ and 11 . In further experiments, the reaction temperature and $\mathrm{pH}$ were adjusted to $50^{\circ} \mathrm{C}$ and 7 , respectively, as the optimal conditions.

In the ATP-dependent reactions, metal ions are often necessary as cofactors for the main enzyme for effective synthesis of ATP $[37,38]$. Thus, many types of metal ions were investigated to identify the most effective factor during the whole-cell reaction (Fig. 2C). Among these metal ions, $\mathrm{Mn}^{2+}, \mathrm{Co}^{2+}, \mathrm{Mg}^{2+}, \mathrm{Zn}^{2+}$, and $\mathrm{Ca}^{2+}$ were found to
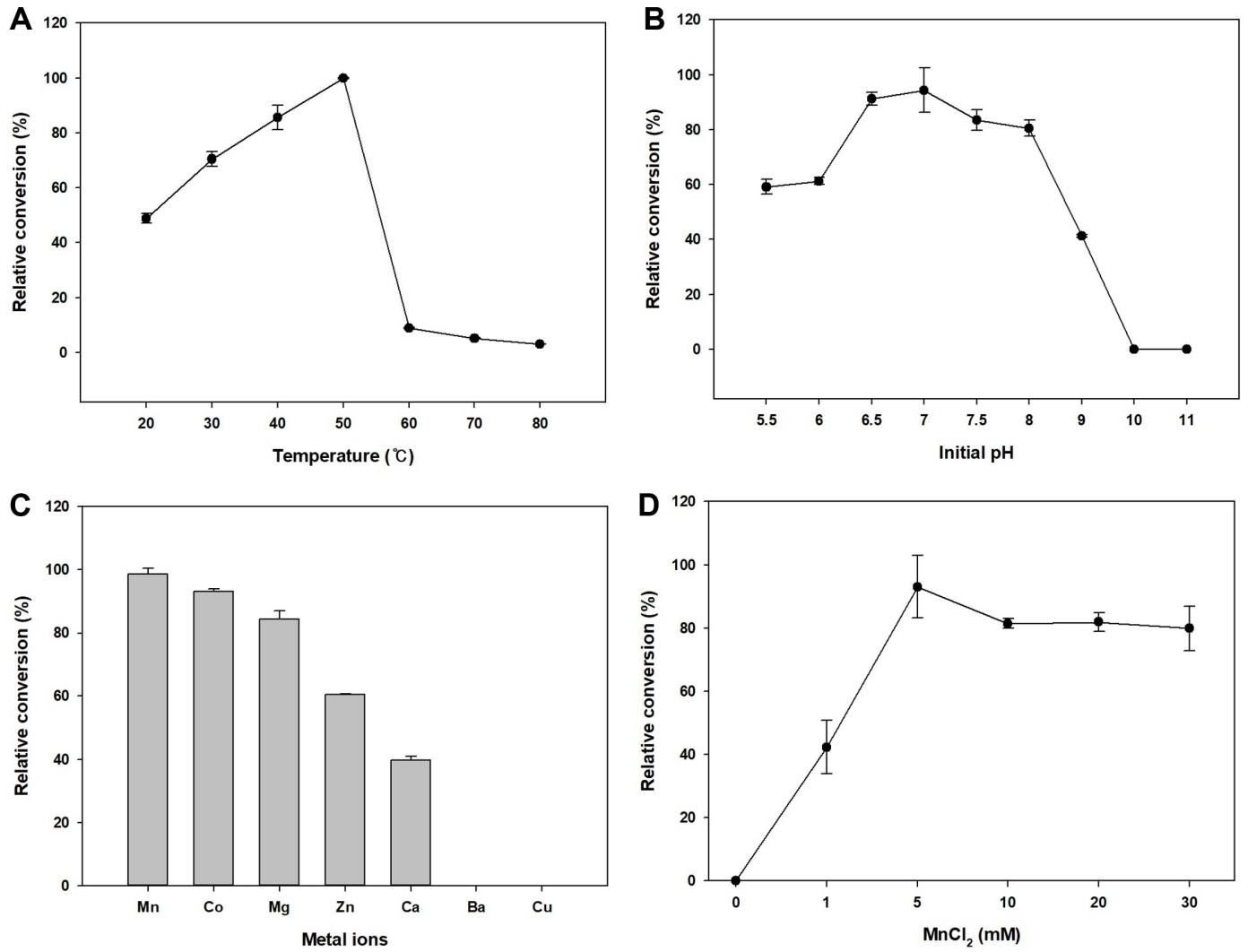

Fig. 2. Optimization of whole-cell reaction conditions. Optimal temperature was evaluated from $20^{\circ} \mathrm{C}$ to $80^{\circ} \mathrm{C}(\mathrm{A})$ and optimal initial $\mathrm{pH}$ was evaluated from 5.5 to 11 (B). Various metal ions were investigated (C) and optimal $\mathrm{MnCl}_{2} \mathrm{was}_{\text {found }}(\mathbf{D})$. 

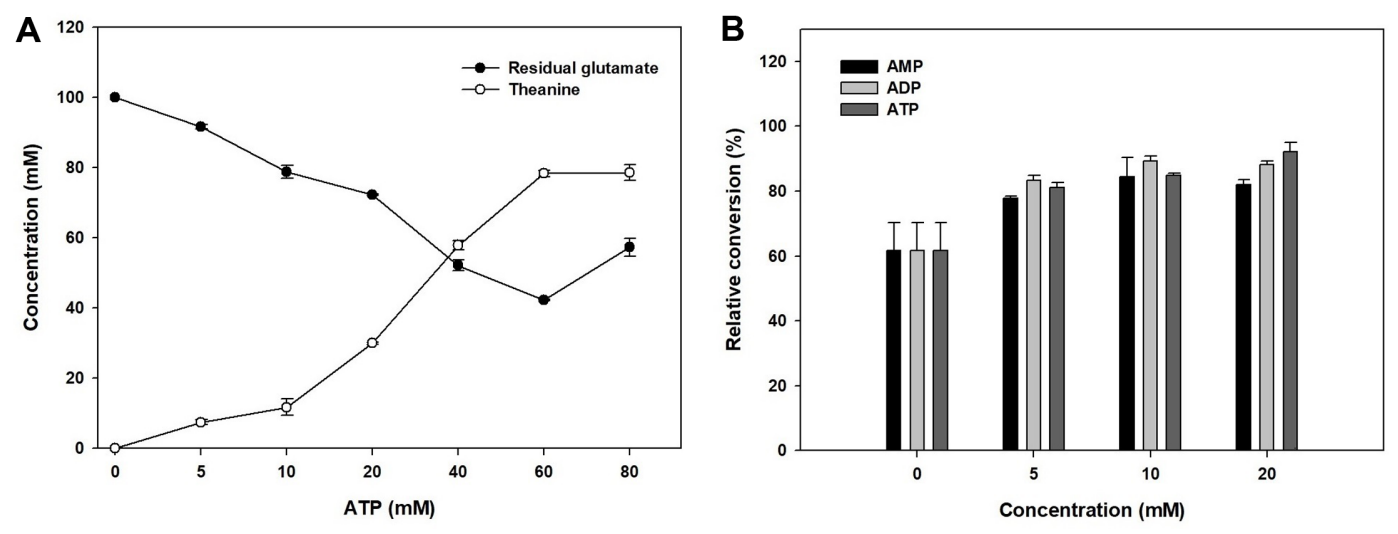

Fig. 3. The effect of different ATP concentration on the production of L-theanine by the GMAS enzyme. Optimal ATP concentration was determined by detecting glutamate and L-theanine (A) and the effects of ATP, ADP, and AMP. All components were tested at various concentrations (B).

influence the reaction. Particularly, the reaction with $\mathrm{Mn}^{2+}$ could produce 2.4-fold higher L-theanine than that with $\mathrm{Ca}^{2+}$. However, activities were not observed when $\mathrm{Ba}^{2+}$ and $\mathrm{Cu}^{2+}$ were utilized. To determine the optimal concentration of $\mathrm{Mn}^{2+}, \mathrm{MnCl}_{2}$ was fed into the reactant to the desired concentration (Fig. 2D). As a result, the reaction containing $5 \mathrm{mM} \mathrm{MnCl}_{2}$ could produce the largest amount of L-theanine. Additionally, $10 \mathrm{mM} \mathrm{MgCl}_{2}$ had positive effect in L-theanine production when we fixed ATP and $\mathrm{MnCl}_{2}$ concentrations (Fig. S1). Thus, $5 \mathrm{mM}$ $\mathrm{MnCl}_{2}$ and $10 \mathrm{mM} \mathrm{MgCl}$ were used in further experiments.

\section{Effect of Co-Factors on Reaction}

To confirm the effects of ATP on the GMAS enzyme, different concentrations of ATP were utilized for Ltheanine production (Fig. 3A). The substrate level was $100 \mathrm{mM}$ and $\mathrm{pH}$ was $\mathrm{pH}$ 7. No conversion was observed in the absence of ATP and glutamate also remained as initial substrates. As the concentration increased, L-theanine was also increased gradually. Approximately $80 \mathrm{mM}$ L-theanine was achieved with $80 \%$ conversion when more than $60 \mathrm{mM}$ ATP was used. These data indicate that GMAS is an ATP-dependent enzyme.

We also tested other kinds of energy sources such as ADP and AMP for comparison with ATP in L-theanine production (Fig. 3B). AMP or ADP can be used as energy source because we introduced an ATP regeneration system. Therefore, the source most effective for L-theanine production was evaluated. When these factors were compared to the control which contained no sources of ATP, the conversion yields were greater than control in all parameters. The use of AMP resulted in lower conversion yields than the other sources at all concentrations. Thus, we used ATP considering its lower cost, although ADP and ATP showed similar conversion yields.

\section{Effects of Baker's Yeast and Phosphate for ATP Regeneration}

Various strains were cultivated with the whole-cell reaction for energy transfer (Fig. 4A). Then, we added $200 \mathrm{mM}$ glucose for cell growth. Among them, baker's yeast was the most effective for ATP synthesis, which leaded to the highest production of L-theanine. The relative conversion of E. coli, Pseudomonas putida, and Bacillus subtilis were nearly half of that from baker's yeast. Corynebacterium glutamicum showed slightly higher than those of activity with $53 \%$ relative conversion.

To clarify the effects of baker's yeast on ATP regeneration, whole-cell reactions were compared after adding baker's yeast (Fig. 4B). Approximately 3.8-fold higher L-theanine levels were obtained in the static reaction. When we increased the reaction speed to $1,200 \mathrm{rpm}, 4.3$-fold higher L-theanine was produced, which was more efficient than in the static reaction. Thus, ATP regeneration shows better results when the baker's yeast is added for respiration than for fermentation.

In the reaction using sugar fermentative methods with baker's yeast, phosphate sources are necessary to enhance production. Therefore, polyphosphate and potassium phosphate were tested (Figs. 4C and 4D). Additionally, some treatments were carried out to evaluate cell permeability, which facilitates the transport of substrates and product. Cetyl trimethyl ammonium bromide (CTAB), polyoxyethylene sorbitan monooleate (Tween 80), and sonicated whole-cell (cell extract) were compared to the whole-cell system. Among them, the cell extract showed low L-theanine production. Additionally, activities using the whole-cell were similar to those of the whole-cell treated with CTAB and Tween 80 . However, polyphosphate slightly influenced conversion yields compared to the control, which showed a 1.8-fold higher value in the presence of $10 \mathrm{mM}$ polyphosphate than the control. To enhance the titers, additional phosphatases are needed to convert the polymers into monomers. In contrast, potassium phosphate was greatly effective for increased the production of L-theanine. Conversion yields were approximately 4 -fold higher than those of the control in the presence of $300 \mathrm{mM}$ potassium phosphate. When we tested sodium phosphate, L-theanine production was lower than that after potassium phosphate addition (Fig. S2). 

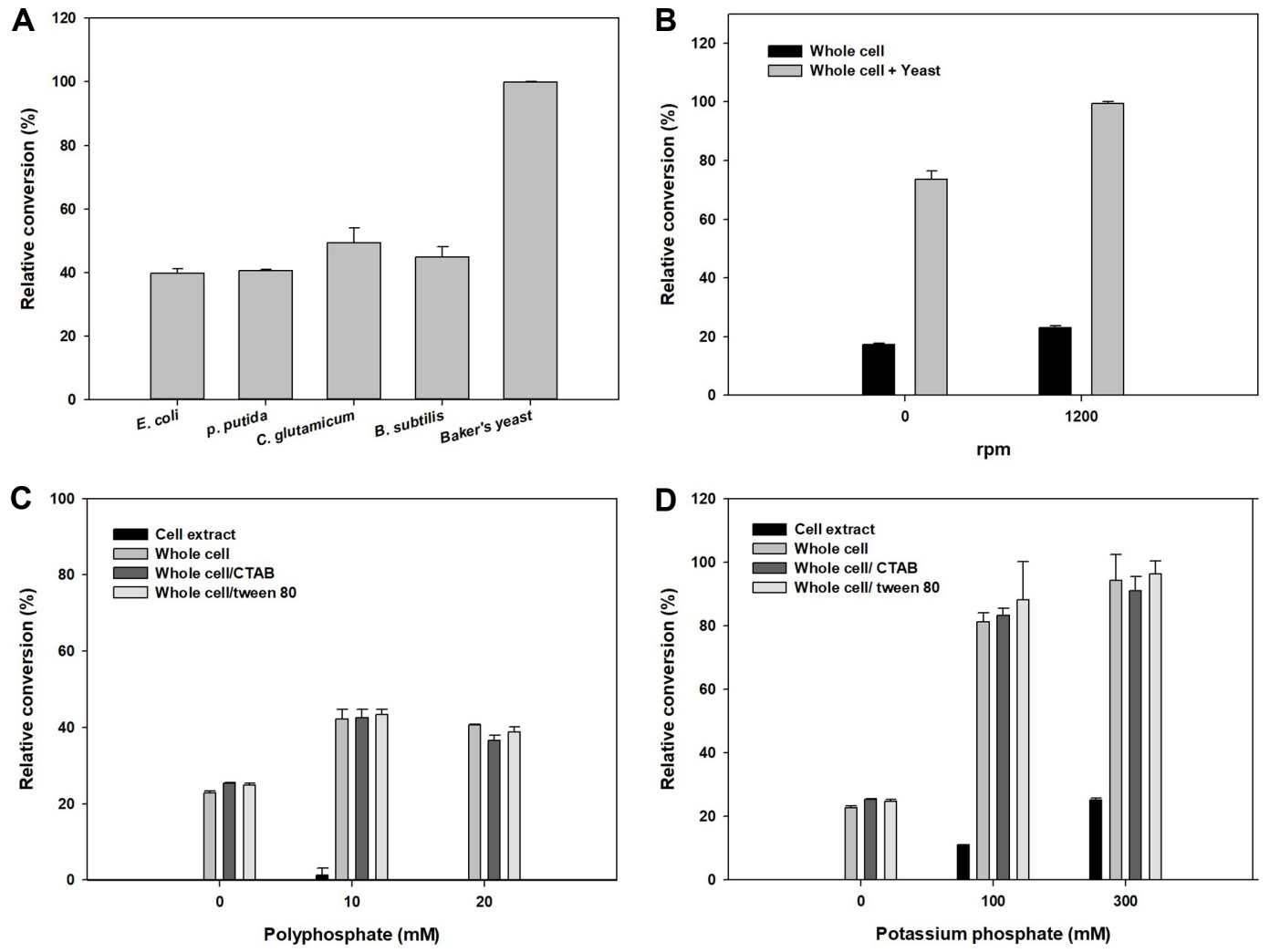

Fig. 4. Effect of baker's yeast for ATP regeneration. Various strains were cultivated during the reactions for ATP regeneration (A). Activities were checked in comparison between control reaction and reaction containing baker's yeast depending on rpm rates (B). The effects of phosphate sources were examined by $E$. coli whole-cell and baker's yeast using polyphosphate $(\mathbf{C})$ and potassium phosphate $(\mathbf{D})$

Enhanced L-Theanine Production by Repetitive Use and Additional GMAS Expression

To examine the reusability of GMAS enzyme for the repetitive use of the whole-cell, the cell was recycled 3 times (Fig. 5A). The L-theanine concentration after each cycle and the accumulated L-theanine were monitored. The reactants containing cells were centrifuged after $24 \mathrm{~h}$, and then the reacted medium was replaced with fresh substrate medium. After the first cycle, $161 \mathrm{mM} \mathrm{L}$-theanine was recorded from $200 \mathrm{mM}$ substrates. The produced L-theanine concentration was decreased by 0.51 - and 0.26 -fold in the second and third cycles, respectively. The total amount of L-theanine was obtained until $286.3 \mathrm{mM}$ in 3 cycles.

Cells harboring pXMJ19::gmas exhibited activities as high as those of BW25113 (DE3) harboring pET24ma::gmas according to previous data and the repetitive use of the whole-cells. Therefore, the additional vector was inserted
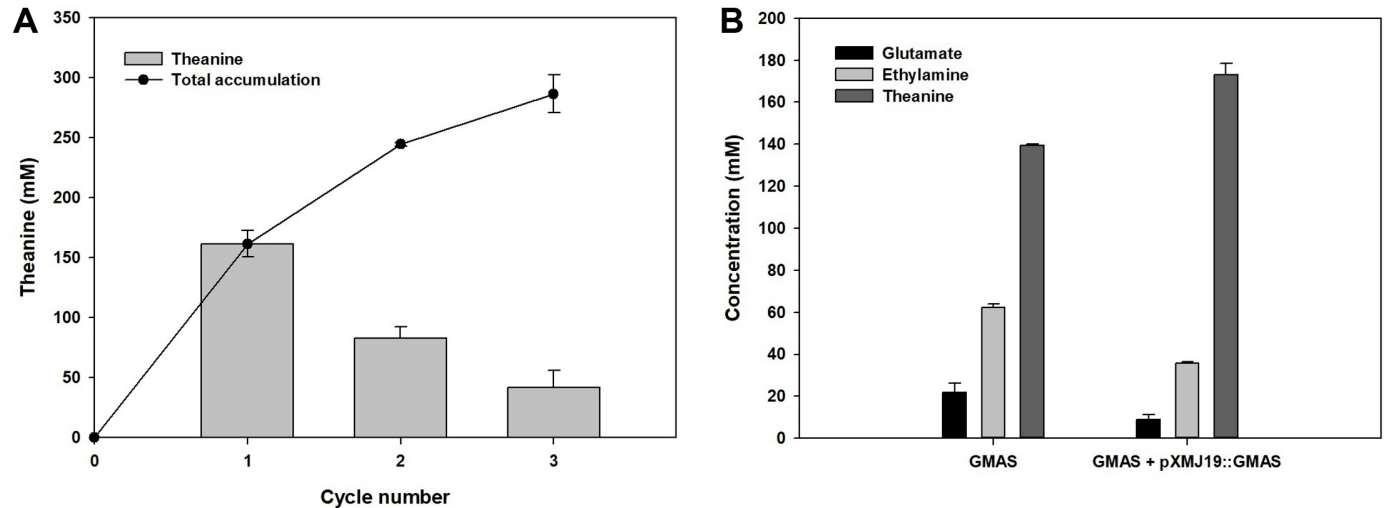

Fig. 5. Enhanced production by repeating GMAS whole-cell for accumulation of L-theanine (A) and overexpressing additional gmas gene (B). 


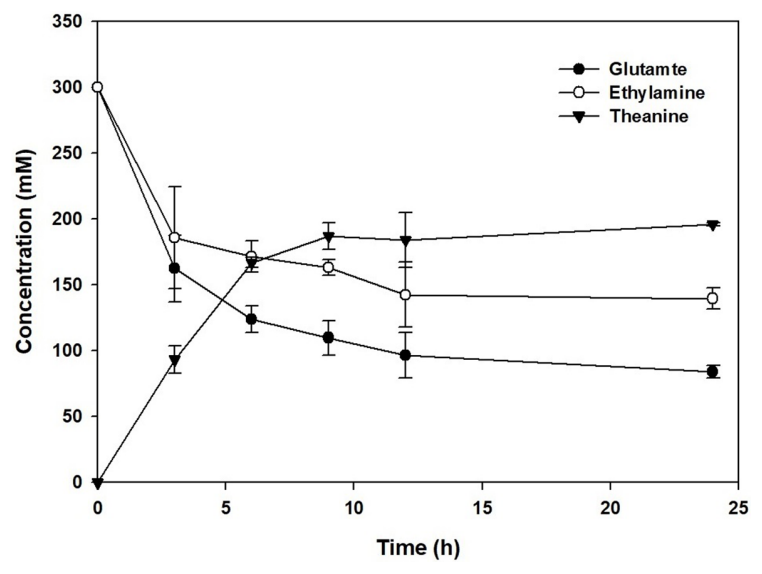

Fig. 6. L-theanine production monitoring by time-dependent manner under optimized concentration of substrates and co-factor.

into BW25113 (DE3) harboring pET24ma::gmas. When the substrate concentration was $200 \mathrm{mM}$, approximately $140 \mathrm{mM}$ L-theanine was obtained with 70\% conversion (Fig. 5B). After pXMJ19::gmas was introduced, production increased to $178 \mathrm{mM}$ with $89 \%$ conversion while substrate consumption also increased. Accordingly, we found that additional GMAS expression affects positively to enhance $\mathrm{L}$-theanine production.

Finally, the time-dependence of the reaction was carried out with BW25113 (DE3) overexpressing pXMJ19::gmas and pET24ma::gmas. The reaction was performed with $300 \mathrm{mM}$ glutamate, $300 \mathrm{mM}$ ethylamine, $200 \mathrm{mM}$ glucose, $60 \mathrm{mM}$ ATP, $5 \mathrm{mM} \mathrm{MnCl}$, $10 \mathrm{mM} \mathrm{MgCl}, 300 \mathrm{mM}$ potassium phosphate and $40 \mathrm{mg} / \mathrm{ml}$ baker's yeast (Fig. 6). Because most substrates were converted to L-theanine in the previous data (Fig. 5B), we increased the substrate level to $300 \mathrm{mM}$. Glutamate and ethylamine as the substrates started to be consumed after $3 \mathrm{~h}$. After the reaction was complete, approximately $100 \mathrm{mM}$ glutamate and $148 \mathrm{mM}$ ethylamine remained. $198 \mathrm{mM}$ L-theanine could be achieved within $12 \mathrm{~h}$ We conclude L-theanine can be produced by $16.5 \mathrm{mmol} / \mathrm{l} / \mathrm{h}$ productivity.

Many studies have been conducted to evaluate the use of various enzymes for L-theanine production. LTheanine exhibits effects such as anti-tumor, relaxation, and enhanced immunity. Previous reports show that among the enzymes used in L-theanine synthesis, GMAS shows potential for application in industrial production. However, the process of GMAS enzyme purification is difficult, costly, and time-consuming. In contrast, the whole-cell is easy to handle and does not require complicated procedures for its preparation. Therefore, the wholecell reaction involving GMAS has greatest potential for scale-up production of L-theanine.

To construct a whole-cell system for L-theanine, protein expression and the reaction conditions were optimized. Additionally, the effect of baker's yeast in ATP regeneration was clarified. Additional expression was also efficient for enhancing L-theanine production. To our knowledge, this is the first application of a whole-cell reaction of GMAS to develop an L-theanine production system.

\section{Acknowledgments}

This work was supported by Research Program to solve social issues of the National Research Foundation of Korea (NRF) funded by the Ministry of Science and ICT (2017M3A9E4077234) and National Research Foundation of Korea (NRF) (NRF-2017R1D1A1B03033594, NRF-2019M3E6A1103979 and NRF2019R1F1A1058805). In addition, this work was also supported by the polar academic program (PAP, PE18900). This paper was also supported by Konkuk University Researcher Fund in 2019. Consulting service from the Microbial Carbohydrate Resource Bank (MCRB, Korea) was kindly appreciated.

\section{Conflict of Interest}

The authors have no financial conflicts of interest to declare.

\section{References}

1. Zheng G, Sayama K, Okubo T, Juneja LR, Oguni I. 2004. Anti-obesity effects of three major components of green tea, catechins, caffeine and theanine, in mice. In Vivo 18: 55-62.

2. Turkozu D, Sanlier N. 2017. L-theanine, unique amino acid of tea, and its metabolism, health effects, and safety. Crit. Rev. Food Sci. Nutr. 57: 1681-1687.

3. Saeed M, Naveed M, Arif M, Kakar MU, Manzoor R, Abd El-Hack ME, et al. 2017. Green tea (Camellia sinensis) and l-theanine: Medicinal values and beneficial applications in humans-A comprehensive review. Biomed. Pharmacother. 95: 1260-1275.

4. Adhikary R, Mandal V. 2017. L-theanine: A potential multifaceted natural bioactive amide as health supplement. Asian Pac. J. Trop. Biomed. 7: 842-848.

5. Vuong QV, Stathopoulos CE, Golding JB, Nguyen MH, Roach PD. 2011. Optimum conditions for the water extraction of L-theanine from green tea. J. Sep. Sci. 34: 2468-2474.

6. Vuong QV, Bowyer MC, Roach PD. 2011. L-Theanine: properties, synthesis and isolation from tea. J. Sci. Food Agric. 91: 1931-1939.

7. Kawagishi H, Sugiyama K. 1992. Facile and large-scale synthesis of L-Theanine. Biosci. Biotechnol. Biochem. 56: 689. 
8. Shuai Y, Zhang T, Jiang B, Mu W. 2010. Development of efficient enzymatic production of theanine by gamma-glutamyltranspeptidase from a newly isolated strain of Bacillus subtilis, SK11.004. J. Sci. Food Agric. 90: 2563-2567.

9. Tachiki T, Yamada T, Mizuno K, Ueda M, Shiode J, Fukami H. 1998. gamma-glutamyl transfer reactions by glutaminase from Pseudomonas nitroreducens IFO 12694 and their application for the syntheses of theanine and gamma-glutamylmethylamide. Biosci. Biotechnol. Biochem. 62: 1279-1283.

10. Mu W, Zhang T, Jiang B. 2015. An overview of biological production of L-theanine. Biotechnol. Adv. 33: 335-342.

11. Chen X, Su L, Wu D, Wu J. 2014. Application of recombinant Bacillus subtilis $\gamma$-glutamyltranspeptidase to the production of 1theanine. Process Biochem. 49: 1429-1439.

12. Pu H, Wang Q, Zhu F, Cao X, Xin Y, Luo L, et al. 2013. Cloning, expression of glutaminase from Pseudomonas nitroreducens and application to theanine synthesis. Biocatal. Biotransform. 31: 1-7.

13. Sharma E, Joshi R, Gulati A. 2018. l-Theanine: An astounding sui generis integrant in tea. Food Chem. 242: 601-610.

14. Liu S, Li Y, Zhu J. 2016. Enzymatic production of l-theanine by $\gamma$-glutamylmethylamide synthetase coupling with an ATP regeneration system based on polyphosphate kinase. Process Biochem. 51: 1458-1463.

15. Berke W, Schüz HJ, Wandrey C, Morr M, Denda G, Kula MR. 1988. Continuous regeneration of ATP in enzyme membrane reactor for enzymatic syntheses. Biotechnol. Bioeng. 32: 130-139.

16. Endo T, Koizumi S. 2001. Microbial conversion with cofactor regeneration using genetically engineered bacteria. Adv. Synth. Catal. 343: 521-526.

17. Moon Y-M, Yang SY, Choi TR, Jung H-R, Song H-S, hoon Han Y, et al. 2019. Enhanced production of cadaverine by the addition of hexadecyltrimethylammonium bromide to whole cell system with regeneration of pyridoxal-5'-phosphate and ATP. Enzyme Microb. Technol. 127: 58-64.

18. Wei LL, Goux WJ. 1992. ATP cofactor regeneration via the glycolytic pathway. Bioorg. Chem. 20: 62-66.

19. Sato M, Masuda Y, Kirimura K, Kino K. 2007. Thermostable ATP regeneration system using polyphosphate kinase from Thermosynechococcus elongatus BP-1 for D-amino acid dipeptide synthesis. J. Biosci. Bioeng. 103: 179-184.

20. Kameda A, Shiba T, Kawazoe Y, Satoh Y, Ihara Y, Munekata M, et al. 2001. A novel ATP regeneration system using polyphosphateAMP phosphotransferase and polyphosphate kinase. J. Biosci. Bioeng. 91: 557-563.

21. Yan B, Ding Q, Ou L, Zou Z. 2014. Production of glucose-6-phosphate by glucokinase coupled with an ATP regeneration system. World J. Microbiol. Biotechnol. 30: 1123-1128.

22. Resnick SM, Zehnder AJ. 2000. In vitro ATP regeneration from polyphosphate and AMP by polyphosphate: AMP phosphotransferase and adenylate kinase from Acinetobacter johnsonii 210A. Appl. Environ. Microbiol. 66: 2045-2051.

23. Wakisaka S, Ohshima Y, Ogawa M, Tochikura T, Tachiki T. 1998. Characteristics and efficiency of glutamine production by coupling of a bacterial glutamine synthetase reaction with the alcoholic fermentation system of baker's yeast. Appl. Environ. Microbiol. 64: 2952-2957.

24. Horinouchi N, Sakai T, Kawano T, Matsumoto S, Sasaki M, Hibi M, et al. 2012. Construction of microbial platform for an energyrequiring bioprocess: practical 2 '-deoxyribonucleoside production involving a $\mathrm{C}-\mathrm{C}$ coupling reaction with high energy substrates. Microb. Cell Fact. 11: 82.

25. Matsuno R, Asada M, Nakanishi K, Kamikubo T. 1982. ATP Regeneration by Enzymes of Alcohol Fermentation and Kinases of Yeast and its Computer Simulation, pp. 351-352. Enzyme Engineering, Ed. Springer

26. Horinouchi N, Ogawa J, Kawano T, Sakai T, Saito K, Matsumoto S, et al. 2006. Efficient production of 2-deoxyribose 5-phosphate from glucose and acetaldehyde by coupling of the alcoholic fermentation system of Baker's yeast and deoxyriboaldolase-expressing Escherichia coli. Biosci. Biotechnol. Biochem. 70: 1371-1378.

27. Yamamoto S, Wakayama M, Tachiki T. 2005. Theanine production by coupled fermentation with energy transfer employing Pseudomonas taetrolens Y-30 glutamine synthetase and baker's yeast cells. Biosci. Biotechnol. Biochem. 69: 784-789.

28. Lin J-P, Tian J, You J-F, Jin Z-H, Xu Z-N, Cen P-L. 2004. An effective strategy for the co-production of S-adenosyl-L-methionine and glutathione by fed-batch fermentation. Biochem. Eng. J. 21: 19-25.

29. Bhatia SK, Bhatia RK, Yang Y-H. 2016. Biosynthesis of polyesters and polyamide building blocks using microbial fermentation and biotransformation. Rev. Environ. Sci. Bio/Technol. 15: 639-663.

30. Yang S-Y, Choi T-R, Jung H-R, Park Y-L, Han Y-H, Song H-S, et al. 2020. Development of glutaric acid production consortium system with a-ketoglutaric acid regeneration by glutamate oxidase in Escherichia coli. Enzyme Microb. Technol. 133: 109446.

31. Moon Y-M, Gurav R, Kim J, Hong Y-G, Bhatia SK, Jung H-R, et al. 2018. Whole-cell immobilization of engineered Escherichia coli JY001 with barium-alginate for itaconic acid production. Biotechnol. Bioprocess Eng. 23: 442-447.

32. Bhatia SK, Shim Y-H, Jeon J-M, Brigham CJ, Kim Y-H, Kim H-J, et al. 2015. Starch based polyhydroxybutyrate production in engineered Escherichia coli. Bioprocess Biosys. Eng. 38: 1479-1484.

33. Bhatia SK, Kim S-H, Yoon J-J, Yang Y-H. 2017. Current status and strategies for second generation biofuel production using microbial systems. Energy Convers. Manage 148: 1142-1156.

34. Alaiz M, Navarro JL, Girón J, Vioque E. 1992. Amino acid analysis by high-performance liquid chromatography after derivatization with diethyl ethoxymethylenemalonate. J. Chromatogr. 591: 181-186.

35. Kim J, Seo H-M, Bhatia SK, Song H-S, Kim J-H, Jeon J-M, et al. 2017. Production of itaconate by whole-cell bioconversion of citrate mediated by expression of multiple cis-aconitate decarboxylase (cadA) genes in Escherichia coli. Sci. Rep. 7: 39768.

36. Griffiths MW, Muir DD. 1978. Properties of a thermostable $\beta$-galactosidase from a thermophilic Bacillus: Comparison of the enzyme activity of whole cells, purified enzyme and immobilised whole cells. J. Sci. Food Agric. 29: 753-761.

37. Buchachenko AL, Kuznetsov DA. 2008. Magnetic field affects enzymatic ATP synthesis. J. Am. Chem. Soc. 130: 12868-12869.

38. Moon Y-M, Yang SY, Choi TR, Jung H-R, Song H-S, hoon Han Y, et al. 2019. Enhanced production of cadaverine by the addition of hexadecyltrimethylammonium bromide to whole cell system with regeneration of pyridoxal-5'-phosphate and ATP. Enzyme Microb. Technol. 127: 58-64.

39. Taylor RG, Walker DC, McInnes R. 1993. E. coli host strains significantly affect the quality of small scale plasmid DNA preparations used for sequencing. Nucleic Acids Res. 21: 1677.

40. Lobstein J, Emrich CA, Jeans C, Faulkner M, Riggs P, Berkmen M. 2012. SHuffle, a novel Escherichia coli protein expression strain capable of correctly folding disulfide bonded proteins in its cytoplasm. Microb. Cell Fact. 11: 753.

41. Lee SG, Lee JO, Yi JK, Kim BG. 2002. Production of cytidine 5'-monophosphate N-acetylneuraminic acid using recombinant Escherichia coli as a biocatalyst. Biotechnol. Bioeng. 80: 516-524.

42. Jakoby M, Ngouoto-Nkili C-E, Burkovski A. 1999. Construction and application of new Corynebacterium glutamicum vectors. Biotechnol. Tech. 13: 437-441. 